\title{
Littérature québécoise en regard des autres littératures francophones, dossier a cura di Lise Gauvin
}

\section{Carminella Biondi}

\section{(2) OpenEdition}

1 Journals

\section{Edizione digitale}

URL: http://journals.openedition.org/studifrancesi/6115

DOI: $10.4000 /$ studifrancesi.6115

ISSN: 2421-5856

\section{Editore}

Rosenberg \& Sellier

\section{Edizione cartacea}

Data di pubblicazione: 1 mai 2011

Paginazione: 219

ISSN: 0039-2944

\section{Notizia bibliografica digitale}

Carminella Biondi, «Littérature québécoise en regard des autres littératures francophones, dossier a cura di Lise Gauvin», Studi Francesi [Online], 163 (LV | I) | 2011, online dal 30 novembre 2015, consultato il 13 janvier 2021. URL: http://journals.openedition.org/studifrancesi/6115 ; DOI: https://doi.org/10.4000/ studifrancesi.6115

Questo documento è stato generato automaticamente il 13 janvier 2021.

\section{(c) (1)}

Studi Francesi è distribuita con Licenza Creative Commons Attribuzione - Non commerciale - Non opere derivate 4.0 Internazionale. 


\title{
Littérature québécoise en regard des autres littératures francophones, dossier a cura di Lise Gauvin
}

\author{
Carminella Biondi
}

\section{NOTIZIA}

Littérature québécoise en regard des autres littératures francophones, dossier a cura di Lise GAUVIN, «Québec Studies», n. 49, primavera/estate 2010, pp. 3-58.

1 Questo importante dossier, curato da Lise Gauvin, che vede il contributo di noti studiosi, non vuole essere soltanto una messa a punto dei rapporti tra la letteratura quebecchese ed altre letterature francofone - è indubbiamente anche questo - ma ha mire più ambiziose, come dice esplicitamente la curatrice nella sua introduzione: vuole essere in un certo senso la continuazione, in prospettiva quebecchese, del discorso aperto dagli scrittori del manifesto Pour une littérature-monde en langue française (lanciato su «Le Monde», nel marzo 2007, firmato da quarantaquattro scrittori, poi approfondito nel volume dallo stesso titolo, pubblicato da Gallimard nel maggio dello stesso anno). Dunque un contributo alla discussione attorno al concetto di francofonia letteraria, che sembra ormai stare stretto agli scrittori provenienti dalle diverse aree di lingua francese. Senza contare che il termine è ambiguo visto che talvolta è utilizzato per indicare tutti gli scrittori di lingua francese, ivi compresi quelli dell'esagono, talaltra, sulla base si una scelta percepita ormai come una forma di marginalizzazione, soltanto gli scrittori extra-esagono, che comunque devono sempre passare da Parigi per il loro riconoscimento. Secondo Lise Gauvin, il manifesto è il risultato di questo malessere: «On y sonnait le glas de la francophonie entendue comme 'le dernier avatar du colonialisme'» (p. 3). A suo avviso si tratta di un contributo fondamentale alla rilettura di tutte le problematiche concernenti la francofonia letteraria, ma la studiosa non può esimersi dal notare, come hanno fatto altri critici, che «La notion de 
'littérature-monde' est [...] élaborée au cœur même de cette institution [parisienne], dont elle reproduit le caractère franco-centriste» (p. 5).

2 Il dossier curato da Lise Gauvin si colloca all'interno di questo dibattito complesso, e tuttora molto vivace, con quattro interventi, oltre all'introduzione già citata (Enjeux et configuration d'un rhizome, pp. 3-7): L'épopée des Amériques - Miron, Césaire, Saint-John Perse di Dominique COMBE (pp. 9-21); Le modèle Belge di Michel BIRON (pp. 23-29), Enseignement et circulation littéraire. L'interlisibilité des textes francophones di micheline CAMBRON (pp. 31-45); (In) (ter)dépendance des littératures francophones du Canada di Benoit DoYoNgosselin (pp. 47-58). Il saggio di Dominique Combe, noto studioso di letterature francofone (Poétiques francophones, Hachette, 1995; Les littératures francophones Questions, débats, polémiques, PUF, 2010), pur focalizzato su tre autori americani di lingua francese, pone un problema di ordine più generale sul genere epico, in particolare nelle letterature americane, ma il suo discorso potrebbe essere avvicinato a quello di Édouard Glissant che assegna all'epopea un ruolo centrale nella scrittura del Toutmonde. Il testo di Michel Biron rileva analogie e differenze fra la letteratura belga e quella quebecchese nel loro modo di porsi nei confronti del comune modello di riferimento obbligato, almeno in passato, vale a dire la letteratura francese. Segue il saggio di Micheline Cambron che indica molto chiaramente, in apertura di discorso, il problema che si propone di affrontare e la prospettiva di approccio: «Il y a plusieurs façons de s'interroger sur la circulation des littératures francophones dans leurs espaces respectifs et sur la façon dont ces littératures entretiennent entre elles un commerce original, détaché ou non de l'entremise de la littérature française. [...] Je propose [...] de baliser cette question de la circulation du point de vue de la lecture, en mettant le foyer sur la mise en circulation des œuvres dans le contexte scolaire» (p. 31). In conclusione Benoit Doyon-Gosselin si sofferma sui rapporti che intercorrono fra la letteratura quebecchese (dominante all'interno della letteratura franco-canadese) e le letterature dell'Acadia, dell'Ontario e del Manitoba, rilevando che si ripropone qui, in dimensioni ridotte, il rapporto squilibrato esistente tra la letteratura di Francia e le altre letterature di lingua francese.

Il dossier meriterebbe un'analisi critica più approfondita, ma ci auguriamo che questa schematica sintesi ne abbia evidenziato l'interesse all'interno dell'attuale dibattito sulla francofonia letteraria, dibattito che Lise Gauvin conosce molto bene avendo, tra l'altro, appena curato la pubblicazione degli atti di un convegno su Les littératures de langue française à l'heure de la mondialisation (Montréal, HMH, 2010). 